\title{
AGE AND HEALTH RELATED NON- LINEAR INHERITANCE TAXATION
}

Marie-Louise Leroux, Pierre Pestieau

\section{LIDAM Discussion Paper CORE $2021 / 02$}




\section{CORE}

Voie du Roman Pays 34, L1.03.01

B-1348 Louvain-la-Neuve

Tel (32 10) 474304

Email: immaq-library@uclouvain.be

https://uclouvain.be/en/research-institutes/lidam/core/core-discussion-papers.html 


\title{
Age and health related non-linear inheritance taxation.
}

\author{
Marie-Louise Leroux* Pierre Pestieau ${ }^{\dagger}$
}

November 8, 2021

\begin{abstract}
This paper studies the design of an optimal non linear inheritance taxation when individuals differ in wage as well as in their risks of both mortality and old-age dependance. Agents with higher wage have higher survival chances and lower chances to become dependent. We assume that the government cannot distinguish between bequests motives, that is whether bequests result from precautionary motives or from pure joy of giving motives. Instead, we assume that it only observes whether bequests are made early in life or late in life, and in the latter case, whether the donor was healthy at time of death. We show that, in order to solve the incentive problem, in addition to a marginal tax on the income of low-productivity individuals, the bequests left by these individuals in case of early death should also be distorted. Under plausible assumptions on demographic characteristics, they should be taxed at the margin. The bequests made later in life need not be taxed or subsidized at the margin.
\end{abstract}

Keywords: Bequest taxation; Long term care; Utilitarianism; Old-age dependency; Non linear taxation.

JEL Codes: H21, H23, I14.

${ }^{*}$ Corresponding author. Département des Sciences Economiques, ESG-UQAM; CORE (UcL, Belgium); CESifo (Munich, Germany). E-mail: leroux.marie-louise@uqam.ca. Financial support from FQRSC and CRSH-SSHRC is gratefully acknowledged.

${ }^{\dagger}$ University of Liege, CORE, and Toulouse School of Economics. Financial support from the Chaire "Marché des risques et création de valeur" of the FdR/SCOR is gratefully acknowledged. 


\section{Introduction}

"I see nothing objectionable in fixing a limit to what anyone may acquire by mere favor of others, without any exercise of his faculties, and in requiring that if he desires any further accession of fortune, he shall work for it." John Stuart Mill (1848)'s argument in favor of inheritance taxation has convinced a lot of thinkers over the years and yet, this form of taxation has never been as unpopular as today. Half of OECD members countries have abolished inheritance taxation. Among them, one finds social democratic Sweden and Norway, Canada and Austria. In OECD countries, the proportion of total government revenues raised by such taxes has fallen since the 1960s from over 1 per cent to less than 0.5 per cent (half of Europe's billionaires have inherited their wealth) 11 There is a puzzle over why inheritance taxes are unpopular relative to other taxes, since they are progressive and, assuming they are spent wisely on welfare goods, more people should gain than lose from inheritance taxation. One of the main reasons why inheritance tax might be unpopular is its design ${ }^{2}$ This tax is plagued by too many loopholes and cases of horizontal inequity. The purpose of this paper is to address one issue concerning the design of the inheritance tax, namely whether the tax rates should vary with the age of the deceased. This question has first been dealt with by Vickrey (1945), who was concerned by the fact that the tax burden was decreasing with the time lag between the occurrences of inheritance ${ }^{3}$ He thus proposed to make bequests taxation depend on the number of years during which donors hold their wealth and to make it increase with the age gap between the donor and the receiver. This was supposed to prevent fiscal arbitrages across generations inside a given family.

Our paper studies whether inheritance taxation should depend on the age of the deceased and on his health state at death, i.e. whether he lived long healthy or dependent. In case of early death, inheritance comprises both a planned and an unplanned component, whereas in case of late death, it only comprises the planned component. Also, when the deceased had to go through long term care (LTC) expenditures, his estate is likely to be lower than that of someone who remained autonomous till the end. If we distinguish between three types of bequests, depending or whether they are left early, late under autonomy or late under dependency, there are opposite arguments to taxing more heavily early bequests. On the one hand, early bequests comprise unintended bequests that are known to be inelastic to taxation 4 But, on the other hand, they concern individuals who unluckily suffer from a short life 5 As to taxing the late bequests of dependent people, there is a good equity argument to tax them less heavily than those of the individuals who remained healthy. Those are intuitive arguments that explain why those three taxes may differ.

\footnotetext{
${ }^{1}$ OECD (2018).

${ }^{2}$ For a survey of the literature, see Cremer and Pestieau (2006).

${ }^{3}$ More recent references are provided below.

${ }^{4}$ On accidental bequests, see Blumkin and Sadka (2003) and Cremer et al. (2012).

${ }^{5}$ This point is developed by Pestieau and Ponthiere (2021) and by Fleurbaey et al. (2021).
} 
In this paper, we study a non-linear taxation problem which accounts for these different arguments. We consider individuals who differ in their productivity, in their survival probability as well as their probability to become dependent. Following Atkinson and Stiglitz (1980), we know that, under asymmetric information, if preferences are separable between consumption and labour, there is no need for any additional tax besides optimal income taxation. This will not be the case in our setting since individuals differ not only in their productivity but also in their risk of early death and their risk of becoming dependent. Additional taxes (or subsidies) on bequests could then be desirable depending on the relation between demographic risks and earnings. On this, the key evidence we rely on comes from Lefebvre et al. (2018), who show that the correlation between income and survival is positive, whereas the correlation between income and the (unconditional) risk to become dependent is negative but small. Using this evidence, we show that, besides income taxation, only the early bequests of the low-productivity individual should be distorted and that in general, they should be taxed at the margin. As we explain in the paper, this is a way to relax self-selection constraints. To the opposite, late bequests (whether, at the time of death, the elderly was healthy or not) should not be taxed at the margin.

These results are in contrast with those of an earlier paper by Leroux and Pestieau (2021), in which the tax instruments are restricted to be linear. In this earlier paper, there is a good case for distorting the three types of bequests and the outcome depends on whether the redistributive effect dominates the insurance effect that aims at equalizing the levels of bequests across the three states of nature. Early bequests are more heavily taxed than the other bequests if the insurance effect dominates the equity effect. In the opposite case, they should be less taxed. Note that it is not unusual to obtain different results when dealing with linear or non-linear taxation problems. The main reason why we obtain results that may look contradictory is that linear taxation provides average taxation rates, which are all identical across individuals with different characteristics, while under non linear taxation, we obtain marginal taxation rates, which, as we show below, are different across agents with different characteristics 6

This paper can be related first to the literature on wealth transfer taxation (among others, Boadway et al., 2000; Cremer et al., 2003; Cremer et al., 2012; Pestieau and Sato, 2008; Brunner and Pech, 2012). As explained in the survey paper of Cremer and Pestieau (2006), and emphasized at the beginning of this paper, the distinction between the different motives is crucial to the design of optimal wealth transfer taxation.7 Also, in this literature, the (non-)observability of wealth and bequest transfers is crucial for the design of the optimal tax structure. Second, our paper contributes to the literature on age-dependent taxation, which was first introduced by Vickrey (1945) ${ }^{8}$ Recently, Fleurbaey et al. (2021) also study the optimal taxation of (voluntary

\footnotetext{
${ }^{6}$ Obviously, a zero marginal taxation rate does not mean that taxation is null.

${ }^{7}$ See for instance Blumkin and Sadka (2003) who study a dynastic model where bequests are motivated by the existence of altruism. Farhi and Werning (2013) also study an optimal estate taxation problem when parents exhibit different degrees of altruism.

${ }^{8}$ For a review of the arguments in favour of making the taxation of bequests vary with the age of the deceased,
} 
and accidental) bequests when individuals have different survival chances, and have a section where the taxation of bequests is made contingent on the age of the deceased. The objective of Fleurbaey et al. (2021) is different from ours in that it concentrates on ex-post compensation of individuals facing different lifespans. The social objective is ex-post egalitarian, i.e. it wants to neutralize ex-post welfare inequalities between agents with different lifespans. Under that framework, the taxation of bequests is used as an instrument to achieve such welfare compensation. Contrary to them, we assume a utilitarian social planner and that individuals with different productivities and different survival chances, also face different risks to become dependent. Apart from Leroux and Pestieau (2021), none of the above papers studying optimal bequest taxation account for the possibility that old-age agents become dependent, something that, given the current demographic trends, is most likely to happen in the future.

The rest of the paper is organized as follows. Section 2 explains the model and analyses the individuals' problem. Section 3 solves the first-best utilitarian problem and Section 4, the second best problem. A final section concludes.

\section{Individuals' problem}

This model features a society that comprises individuals with different types, indexed by $i=$ $\{1, \ldots, N\}$, where each group is composed of $n_{i}$ individuals. They all live at most two periods. The first period is certain but the second one is uncertain. Further, in this second period of life, individuals can be healthy or not. Each type is characterized by a wage, equal to his productivity $w_{i}$, a survival probability $\pi_{i}$ and a dependency risk $p_{i}$. As commonly accepted in the literature, the relationship between $\pi_{i}$ and $w_{i}$ is assumed to be positive $9^{9}$ Also, relying on Lefebvre et al. (2018), we assume that the effect of productivity $w_{i}$ on the probability $\pi_{i} p_{i}$ to become dependent is negative 10

Each individual $i$ supplies an amount of labor $l_{i}$, which creates disutility $h\left(l_{i}\right)$. The disutility of labour is increasing and convex in labour: $h^{\prime}\left(l_{i}\right)>0$ and $h^{\prime \prime}\left(l_{i}\right) \geq 0$. Out of his wage earnings, $y_{i}=w_{i} l_{i}$, each individual finances first-period consumption $c_{i}$, planned bequest $b_{i}$ and saving $s_{i}$ for second-period consumption. In case of autonomy, second-period consumption is denoted by $d_{i}$, while in case of dependency, it is denoted by $m_{i}$. When agents are in good health, consumption utility is denoted by $u($.$) and, it is increasing and concave. When dependent, consumption utility$ is denoted by $H($.$) . This function is increasing and concave and, such that u(z)>H(z) \forall z{ }^{11}$

see Pestieau and Ponthiere (2019).

${ }^{9}$ See for instance, Delavande and Rohwedder (2011) and Lefebvre et al. (2018) who find similar relationship between wealth and survival.

${ }^{10}$ To be precise, Lefebvre et al. (2018) show a positive relationship between wealth and survival, and a negative one between wealth and the occurrence of dependency.

${ }^{11}$ We make no specific assumption on the relationship between $H^{\prime}(z)$ and $u^{\prime}(z)$. Some papers (like Canta et al., 2016; Cremer and Pestieau, 2014; De Donder and Leroux, 2014; De Donder and Pestieau, 2017; Klimaviciute and Pestieau, 2018) assume that $H(z)=u(z-L)$ where $L$ is a monetary loss associated to dependency. In that 
Finally, the joy of giving utility, or equivalently, the utility obtained from leaving bequests, is denoted by $v\left(b_{i}^{j}\right)$ where $j=\{E, L, D\}$ stand for the type of bequests (Early, Late in good health, Dependent). It is increasing and concave in its arguments. Following Hurd (1989), we assume that consuming an amount $z$ always provides more utility to the individual than if he was bequeathing it, i.e. $u(z)>v(z) \forall z \geq 0$, and that the marginal utility from consuming it is also higher than bequeathing it, i.e. $u^{\prime}(z)>v^{\prime}(z) \forall z \geq 0$.

The lifetime utility of an individual $i$ then takes the following form

$$
E U_{i}=u\left(c_{i}\right)-h\left(l_{i}\right)+\pi_{i} p_{i}\left[H\left(m_{i}\right)+v\left(b_{i}^{D}\right)\right]+\pi_{i}\left(1-p_{i}\right)\left[u\left(d_{i}\right)+v\left(b_{i}^{L}\right)\right]+\left(1-\pi_{i}\right) v\left(b_{i}^{E}\right)
$$

where $b_{i}^{E}=\left(b_{i}+s_{i}\right), b_{i}^{L}=\left(b_{i}+x_{i}\right)$ and $b_{i}^{D}=b_{i}$ denote the three different types of bequests.

Throughout the paper, we assume that the rate of interest is zero and that individuals have no time preference. Assuming away any market for annuities and LTC insurance, the utility function of an individual $i$ can then be rewritten as:

$$
\begin{aligned}
E U_{i} & =u\left(w_{i} l_{i}-s_{i}-b_{i}\right)-h\left(l_{i}\right)+\pi_{i} p_{i}\left[H\left(s_{i}\right)+v\left(b_{i}\right)\right]+\left(1-\pi_{i}\right) v\left(b_{i}+s_{i}\right) \\
& +\pi_{i}\left(1-p_{i}\right)\left[u\left(s_{i}-x_{i}\right)+v\left(x_{i}+b_{i}\right)\right]
\end{aligned}
$$

where we replaced for the individual's per period budget constraints. The variable $x_{i}$ is the (additional) amount of saving that an individual who was healthy in the second period of his life, bequeathes to his heir (we come back on this point below).

Two words of clarification on this specification are in order. First, we purposely assume that there is no LTC insurance, nor annuity market. As a consequence, in case of early death, parents leave an amount $s_{i}$ of unplanned bequests besides the planned bequest $b_{i}$ and, individuals choose a saving level higher than what would be needed if $\pi_{i}=0$ or if $p_{i}=0$. Furthermore, if parents happen to be in good health in the second period, they optimally choose to leave an additional transfer $x_{i}$ to their children. If actuarially fair annuities and LTC insurance were available, there would be no accidental bequest $s_{i}$, nor any additional transfer $x_{i}$. In other words, within such an hypothetical setting, the only type of bequests would be intentional (and equal to $b_{i}$ ) and, the issue of differential inheritance taxes would vanish. In addition, in the real world, we only witness a partial annuitisation of retirement saving through defined benefits, public or private, schemes and the extent of LTC insurance, both public and private, is limited 12 This implies that there is room for unintended (equivalently involuntary) bequests. We could introduce those partial schemes in the analysis but as long as they are taken as given, the results would be qualitatively unchanged. In any case, as long as insurance is partial, we are left with different

case, $H^{\prime}(z)>u^{\prime}(z) \forall z$. Some others (like Leroux et al., 2021) assume to the contrary that $u^{\prime}(z)>H^{\prime}(z)$. See also De Donder and Leroux (2021) who assume two types of goods (a daily-life consumption good and health expenditures), and state-dependent preferences.

${ }^{12}$ This is the so-called LTC insurance puzzle. On this, see Brown and Finkelstein (2009) and Pestieau and Ponthiere (2011). 
levels of bequests in the three states of the world and, any optimal fiscal policy will try to reduce the gap between those bequests.

Second, we deliberately opted for a particular type of intended bequests, which arises from a joy of giving motivation. The modelling of the joy of giving utility is similar, for instance, to Fleurbaey et al. (2021), Glomm and Ravikumar (1992), Kopczuk and Lupton (2007) and Piketty and Saez (2013) who also study bequest taxation. Like in these papers, we assume that the parent cares about the amount of bequests received by his heirs after his death, net of taxation. There exist alternative motivations for intended bequest, such as perfect and imperfect altruism and exchange (including strategic bequests). Empirically, it is not clear to assess which motivation is the most relevant 13 For the problem at hand, the exchange motivation does not apply and the altruistic one would imply a dynamic setting that we prefer to avoid in order to keep the analysis tractable.

We assume that the only variables that can be observed are the three different types of bequests, $b_{i}^{E}, b_{i}^{D}$ and $b_{i}^{L}$, gross earnings $y_{i}=w_{i} l_{i}$ and consumption $c_{i}$. We will therefore express the individual's utility in terms of these variables:

$$
\begin{aligned}
E U_{i} & =u\left(c_{i}\right)-h\left({\frac{y}{w_{i}}}_{i}\right)+\pi_{i} p_{i}\left[H\left(b_{i}^{E}-b_{i}^{D}\right)+v\left(b_{i}^{D}\right)\right]+\pi_{i}\left(1-p_{i}\right)\left[u\left(b_{i}^{E}-b_{i}^{L}\right)+v\left(b_{i}^{L}\right)\right] \\
& +\left(1-\pi_{i}\right) v\left(b_{i}^{E}\right)
\end{aligned}
$$

where first-period consumption can be rewritten as follows: $c_{i}=y_{i}-b_{i}^{E}$.

For further use, let us introduce a system of non linear taxes $\theta($.$) on income and bequests so$ that the lifetime utility can be rewritten as 14

$$
\begin{aligned}
E U_{i} & =u\left(y_{i}-\theta\left(y_{i}\right)-b_{i}^{E}-\theta\left(b_{i}^{E}\right)\right)-h\left(\frac{y_{i}}{w_{i}}\right)+\pi_{i} p_{i}\left[H\left(b_{i}^{E}-b_{i}^{D}-\theta\left(b_{i}^{D}\right)\right)+v\left(b_{i}^{D}\right)\right] \\
& +\pi_{i}\left(1-p_{i}\right)\left[u\left(b_{i}^{E}-b_{i}^{L}-\theta\left(b_{i}^{L}\right)\right)+v\left(b_{i}^{L}\right)\right]+\left(1-\pi_{i}\right) v\left(b_{i}^{E}\right) .
\end{aligned}
$$

From the FOCs, we obtain the relevant marginal rates of substitution and the marginal tax

\footnotetext{
${ }^{13}$ For instance, Kopczuk and Lupton (2007) mention that "the evidence suggests motives other than the maximization of a dynastic utility function" (p. 210).

${ }^{14}$ Here, we assume that the non linear tax schedule is separable in $y_{i}$ and $b_{i}^{j}$. Assuming instead a general (non separable) tax schedule $T\left(y_{i}, b_{i}^{E}, b_{i}^{L}, b_{i}^{D}\right)$ would yield the same qualitative results.
} 
rates:

$$
\begin{aligned}
1-\theta^{\prime}\left(y_{i}\right) & =\frac{\frac{1}{w_{i}} h^{\prime}\left(\frac{y_{i}}{w_{i}}\right)}{u^{\prime}\left(c_{i}\right)} \\
1+\theta^{\prime}\left(b_{i}^{E}\right) & =\frac{\pi_{i} p_{i} H^{\prime}\left(m_{i}\right)+\pi_{i}\left(1-p_{i}\right) u^{\prime}\left(d_{i}\right)+\left(1-\pi_{i}\right) v^{\prime}\left(b_{i}^{E}\right)}{u^{\prime}\left(c_{i}\right)} \\
1+\theta^{\prime}\left(b_{i}^{L}\right) & =\frac{v^{\prime}\left(b_{i}^{L}\right)}{u^{\prime}\left(d_{i}\right)} \\
1+\theta^{\prime}\left(b_{i}^{D}\right) & =\frac{v^{\prime}\left(b_{i}^{D}\right)}{H^{\prime}\left(m_{i}\right)} .
\end{aligned}
$$

These trade-offs will be used in order to find the levels of marginal taxation at the second-best optimum (Section 4).

\section{First-best optimum}

Under full information on individuals' types, the utilitarian government will seek to maximize the sum of individuals' utility subject to the resource constraint of the economy. This is thus equivalent to solving the following problem:

$$
\begin{array}{ll}
\max _{c_{i}, y_{i}, b_{i}^{E}, b_{i}^{D}, b_{i}^{L}} & \sum_{i} n_{i}\left\{u\left(c_{i}\right)-h\left(\frac{y}{w}_{i}\right)+\pi_{i} p_{i}\left[H\left(b_{i}^{E}-b_{i}^{D}\right)+v\left(b_{i}^{D}\right)\right]\right. \\
& \left.+\pi_{i}\left(1-p_{i}\right)\left[u\left(b_{i}^{E}-b_{i}^{L}\right)+v\left(b_{i}^{L}\right)\right]+\left(1-\pi_{i}\right) v\left(b_{i}^{E}\right)\right\} \\
\text { s. to } & \sum_{i} n_{i} y_{i} \geq \sum_{i} n_{i}\left(c_{i}+b_{i}^{E}\right)
\end{array}
$$

The last line is the resource constraint of the economy, which amounts to equalizing aggregate earnings $y_{i}$ to first-period consumption $c_{i}$ and early bequests $b_{i}^{E}=\left(b_{i}+s_{i}\right)$.

The FOCs of this problem are:

$$
\begin{aligned}
u^{\prime}\left(c_{i}\right) & =\mu \\
h^{\prime}\left(l_{i}\right) & =\mu w_{i} \\
\pi_{i} p_{i} H^{\prime}\left(b_{i}^{E}-b_{i}^{D}\right)+\pi_{i}\left(1-p_{i}\right) u^{\prime}\left(b_{i}^{E}-b_{i}^{L}\right)+\left(1-\pi_{i}\right) v^{\prime}\left(b_{i}^{E}\right) & =\mu \\
-H^{\prime}\left(b_{i}^{E}-b_{i}^{D}\right)+v^{\prime}\left(b_{i}^{D}\right) & =0 \\
-u^{\prime}\left(b_{i}^{E}-b_{i}^{L}\right)+v^{\prime}\left(b_{i}^{L}\right) & =0 .
\end{aligned}
$$

where $\mu$ is the multiplier associated with the resource constraint.

The first equation above shows that at the first best, $u^{\prime}\left(c_{i}\right)=\mu \forall i$, so that every agent should obtain the same amount of first-period consumption, $\bar{c}$. The second equation shows that higher productivity agents should provide more labour. This is the standard Mirrlees (1971) 
result. In interpreting the conditions on bequests (eq. 8 8 ), it is important to note that the first-best optimum is somehow constrained by the absence of insurance mechanisms that would cover the risk of longevity and that of dependency (as detailed in Section 2). With such devices, both unplanned bequests, $s_{i}$ and the additional gifts, $x_{i}$ in case of a long healthy life would disappear and we would simply have: $b_{i}^{E}=b_{i}^{L}=b_{i}^{D}=b \forall i$. Without these insurance devices, we have condition (8) that establishes an equality between the marginal utility of first-period consumption $u^{\prime}(\bar{c})$ and the weighted average of the marginal utilities of bequests.

Under our assumption that $u^{\prime}(x)>v^{\prime}(x) \forall x$, we obtain from eq. 10 that $d_{i}>b_{i}^{L}$. Assuming that $H^{\prime}()>.u^{\prime}$ (.) (see footnote 11), we then obtain that $H^{\prime}()>.v^{\prime}($.$) and thus, that m_{i}>b_{i}^{D}$. Finally, replacing for (9) and 10 in (8), we can also show that $\bar{c}>b_{i}^{D}, 15$

As to the implementation of the first-best optimum, only interpersonal lump sum transfers would suffice so as to redistribute resources from the high-type individuals toward the low-type ones. No marginal taxation is needed: $\theta^{\prime}\left(y_{i}\right)=\theta^{\prime}\left(b_{i}^{j}\right)=0 \forall i \forall j$.

\section{Second-best optimum and non linear taxation.}

We now turn to the second best problem in which we assume that the planner cannot observe individuals' types but only their distribution in the society. It still observes $\left\{c_{i}, y_{i}, b_{i}^{E}, b_{i}^{D}, b_{i}^{L}\right\}$ for each individual with type $i$. In that situation, it may be the case that more productive individuals are tempted to mimic the less productive ones ${ }^{16}$

In the following, in order to keep the presentation simple, we restrict the analysis to a twotype model, $N=2$, with $w_{2}>w_{1}$. Following Lefebvre et al. (2018), it therefore implies that individual 2 has a higher survival probability and a lower probability to become dependent than individual 1, i.e. $\pi_{2}>\pi_{1}$ and $\pi_{2} p_{2}<\pi_{1} p_{1}{ }^{17}$ The second-best problem consists in solving the

\footnotetext{
${ }^{15}$ To see this recognize that $u^{\prime}(\bar{c})$ is a linear combination of $v^{\prime}\left(b_{i}^{E}\right)$ and $p_{i} v^{\prime}\left(b_{i}^{D}\right)+\left(1-p_{i}\right) v^{\prime}\left(b_{i}^{L}\right)$ with $v^{\prime}\left(b_{i}^{D}\right)>$ $v^{\prime}\left(b_{i}^{L}\right)$. This implies that $v^{\prime}\left(b_{i}^{E}\right)<u^{\prime}(\bar{c})<v^{\prime}\left(b_{i}^{D}\right)$.

${ }^{16}$ This would be the case in particular if differences in productivity dominate differences in the demographic characteristics, since more productive agents work more than less productive ones but obtain the same consumption.

${ }^{17}$ This in turn implies that the conditional probability to become dependent is higher for type- 1 individuals, $p_{1}>p_{2}$.
} 
following problem:

$$
\begin{array}{ll} 
& \max _{c_{i}, y_{i}, b_{i}^{E}, b_{i}^{D}, b_{i}^{L}} \sum_{i} n_{i}\left\{u\left(c_{i}\right)-h\left(\frac{y_{i}}{w_{i}}\right)+\pi_{i} p_{i}\left[H\left(b_{i}^{E}-b_{i}^{D}\right)+v\left(b_{i}^{D}\right)\right]\right. \\
& \left.+\pi_{i}\left(1-p_{i}\right)\left[u\left(b_{i}^{E}-b_{i}^{L}\right)+v\left(b_{i}^{L}\right)\right]+\left(1-\pi_{i}\right) v\left(b_{i}^{E}\right)\right\} \\
\text { s. to } & \sum_{i} n_{i} y_{i} \geq \sum_{i} n_{i}\left(c_{i}+b_{i}^{E}\right) \\
\text { s. to } \quad & u\left(c_{2}\right)-h\left(\frac{y_{2}}{w_{2}}\right)+\pi_{2} p_{2}\left[H\left(b_{2}^{E}-b_{2}^{D}\right)+v\left(b_{2}^{D}\right)\right]+\pi_{2}\left(1-p_{2}\right)\left[u\left(b_{2}^{E}-b_{2}^{L}\right)+v\left(b_{2}^{L}\right)\right]+\left(1-\pi_{2}\right) v\left(b_{2}^{E}\right) \geq \\
& u\left(c_{1}\right)-h\left(\frac{y_{1}}{w_{2}}\right)+\pi_{2} p_{2}\left[H\left(b_{1}^{E}-b_{1}^{D}\right)+v\left(b_{1}^{D}\right)\right]+\pi_{2}\left(1-p_{2}\right)\left[u\left(b_{1}^{E}-b_{1}^{L}\right)+v\left(b_{1}^{L}\right)\right]+\left(1-\pi_{2}\right) v\left(b_{1}^{E}\right)
\end{array}
$$

One can easily check that the optimal trade-offs of type-2 individuals will not be distorted at the second best. In other words, the above first-best conditions (6)-(10) apply, and no distortionary taxation (neither on income nor on bequests) is needed for high-productivity individuals. As to individual 1, some of his choices will be distorted as we now see from the FOCs:

$$
\begin{aligned}
u^{\prime}\left(c_{1}\right)\left(n_{1}-\lambda\right) & =\mu n_{1} \\
-n_{1} h^{\prime}\left(\frac{y_{1}}{w_{1}}\right) \frac{1}{w_{1}}+\lambda h^{\prime}\left(\frac{y_{1}}{w_{2}}\right) \frac{1}{w_{2}} & =-\mu n_{1} \\
n_{1}\left[\pi_{1} p_{1} H^{\prime}\left(b_{1}^{E}-b_{1}^{D}\right)+\pi_{1}\left(1-p_{1}\right) u^{\prime}\left(b_{1}^{E}-b_{1}^{L}\right)+\left(1-\pi_{1}\right) v^{\prime}\left(b_{1}^{E}\right)\right] & \\
-\lambda\left[\pi_{2} p_{2} H^{\prime}\left(b_{1}^{E}-b_{1}^{D}\right)+\pi_{2}\left(1-p_{2}\right) u^{\prime}\left(b_{1}^{E}-b_{1}^{L}\right)+\left(1-\pi_{2}\right) v^{\prime}\left(b_{1}^{E}\right)\right] & =\mu n_{1} \\
n_{1} \pi_{1} p_{1}\left[-H^{\prime}\left(b_{1}^{E}-b_{1}^{D}\right)+v^{\prime}\left(b_{1}^{D}\right)\right]-\lambda \pi_{2} p_{2}\left[-H^{\prime}\left(b_{1}^{E}-b_{1}^{D}\right)+v^{\prime}\left(b_{1}^{D}\right)\right] & =0 \\
n_{1} \pi_{1}\left(1-p_{1}\right)\left[-u^{\prime}\left(b_{1}^{E}-b_{1}^{L}\right)+v^{\prime}\left(b_{1}^{L}\right)\right]-\lambda \pi_{2}\left(1-p_{2}\right)\left[-u^{\prime}\left(b_{1}^{E}-b_{1}^{L}\right)+v^{\prime}\left(b_{1}^{L}\right)\right] & =0
\end{aligned}
$$

where $\lambda$ is the multiplier associated with the self-selection constraint, which ensures that at the second-best optimum, the high-type agents do not mimic the low-type agents.

First, it is obvious that equations (11) and (12) can be combined to obtain that labour income of the low-income individuals should be distorted downward. Comparing it with equation (2) from the decentralisation problem, we obtain that the labour earnings of type- 1 individuals should be taxed at the margin, i.e. $\theta^{\prime}\left(y_{1}\right)>1$, as in Atkinson and $\operatorname{Stiglitz(1980).~}$

Second, equations (14) and 15) imply that there should be no distortion in the choice of $b_{1}^{D}$ and $b_{1}^{L}$. In other words, no marginal taxation of $b_{1}^{D}$ and $b_{1}^{L}$ is required at the second-best optimum: $\theta^{\prime}\left(b_{1}^{L}\right)=0$ and $\theta^{\prime}\left(b_{1}^{D}\right)=0$.

Let us finally turn to the second-best optimal choice of $b_{1}^{E}$ and see whether it should be distorted at the second-best optimum. Using the following notation $A=\pi_{1} p_{1} H^{\prime}\left(b_{1}^{E}-b_{1}^{D}\right)+\pi_{1}(1-$ $\left.p_{1}\right) u^{\prime}\left(b_{1}^{E}-b_{1}^{L}\right)+\left(1-\pi_{1}\right) v^{\prime}\left(b_{1}^{E}\right)$ and $B=\left[\pi_{2} p_{2} H^{\prime}\left(b_{1}^{E}-b_{1}^{D}\right)+\pi_{2}\left(1-p_{2}\right) u^{\prime}\left(b_{1}^{E}-b_{1}^{L}\right)+\left(1-\pi_{2}\right) v^{\prime}\left(b_{1}^{E}\right)\right]$, together with 11 , we can rewrite 13 as follows:

$$
n_{1} A=u^{\prime}\left(c_{1}\right)\left(n_{1}-\lambda\right)+\lambda B
$$


Rearranging terms, we obtain

$$
\frac{A}{u^{\prime}\left(c_{1}\right)}=\frac{1-\frac{\lambda}{n_{1}}}{1-\frac{\lambda}{n_{1}} \frac{B}{A}}
$$

where

$$
\begin{aligned}
\frac{B}{A} & =\frac{\pi_{2} p_{2} H^{\prime}\left(b_{1}^{E}-b_{1}^{D}\right)+\pi_{2}\left(1-p_{2}\right) u^{\prime}\left(b_{1}^{E}-b_{1}^{L}\right)+\left(1-\pi_{2}\right) v^{\prime}\left(b_{1}^{E}\right)}{\pi_{1} p_{1} H^{\prime}\left(b_{1}^{E}-b_{1}^{D}\right)+\pi_{1}\left(1-p_{1}\right) u^{\prime}\left(b_{1}^{E}-b_{1}^{L}\right)+\left(1-\pi_{1}\right) v^{\prime}\left(b_{1}^{E}\right)} \\
& =\frac{\pi_{2} p_{2}\left[H^{\prime}\left(b_{1}^{E}-b_{1}^{D}\right)-u^{\prime}\left(b_{1}^{E}-b_{1}^{L}\right)\right]+\pi_{2}\left[u^{\prime}\left(b_{1}^{E}-b_{1}^{L}\right)-v^{\prime}\left(b_{1}^{E}\right)\right]+v^{\prime}\left(b_{1}^{E}\right)}{\pi_{1} p_{1}\left[H^{\prime}\left(b_{1}^{E}-b_{1}^{D}\right)-u^{\prime}\left(b_{1}^{E}-b_{1}^{L}\right)\right]+\pi_{1}\left[u^{\prime}\left(b_{1}^{E}-b_{1}^{L}\right)-v^{\prime}\left(b_{1}^{E}\right)\right]+v^{\prime}\left(b_{1}^{E}\right)} .
\end{aligned}
$$

Using eq. (14) and (15), we obtain that, in the above equation, all terms are positive since

$$
\begin{aligned}
H^{\prime}\left(b_{1}^{E}-b_{1}^{D}\right)-u^{\prime}\left(b_{1}^{E}-b_{1}^{L}\right) & =v^{\prime}\left(b_{1}^{E}\right)-v^{\prime}\left(b_{1}^{L}\right)>0 \\
u^{\prime}\left(b_{1}^{E}-b_{1}^{L}\right)-v^{\prime}\left(b_{1}^{E}\right) & =v^{\prime}\left(b_{1}^{L}\right)-v^{\prime}\left(b_{1}^{E}\right)>0 .
\end{aligned}
$$

Equation (17) gives the second-best trade-off between first-period consumption and early bequests for type- 1 individuals. If the RHS of (17) is greater than 1 (equiv. if $B / A>1$ ), this trade-off is distorted upward. Comparing the above expression with eq. (3) from the decentralization problem, it implies that $\theta^{\prime}\left(b_{1}^{E}\right)>0$, and it is optimal to tax early bequests. Equivalently, if the RHS of (17) is smaller than 1 (equiv. if $B / A<1$ ), the trade-off is distorted downward and it is optimal to implement a subsidy, i.e. $\theta^{\prime}\left(b_{1}^{E}\right)<0$.

When the probabilities of survival and of dependency are the same for the two types of individuals, $A=B$ and $\theta^{\prime}\left(b_{1}^{E}\right)=0$. In that situation, we are back to the Atkinson-Stiglitz (1980) framework and only labour supply of the low-productivity agent should be taxed in order to solve the incentive problem.

Yet, in our model, individuals have different $\pi_{i}$ and $p_{i}$ so that $A$ and $B$ are likely to be different. In order to understand the results, assume first that $p_{1}=p_{2}=p, \forall i$ so that only survival probabilities are different and such that $\pi_{2}>\pi_{1}$. In equation (18), we have that $B / A>1$, so that $\theta^{\prime}\left(b_{1}^{E}\right)>0$. It is then optimal to set a marginal tax on early bequests of the low-type individual. Assume, on the contrary, that survival probabilities are the same $\pi_{2}=\pi_{1}=\pi \forall i$ so that as shown by Lefebvre et al. (2018), we have that $p_{2}<p_{1}$ (see footnote 17). In that case, $B / A<1$, and a subsidy on early bequests (i.e. $\theta^{\prime}\left(b_{1}^{E}\right)<0$ ) is then optimal.

Finally, in the general case where both $\pi_{i}$ and $p_{i}$ are different across individuals, Lefebvre et al. (2018) have shown that the difference in survival probabilities $\left(\pi_{2}>\pi_{1}\right)$ is larger than the difference in the probabilities to become dependent $\left(\pi_{2} p_{2}<\pi_{1} p_{1}\right)$, which is found to be low. In equation (18), this implies that $B / A>1$, and thus a marginal tax on the early bequests of type-1 individuals, $\theta^{\prime}\left(b_{1}^{E}\right)>0.18$

Our results are summarized in the following proposition and we provide intuitions below.

\footnotetext{
${ }^{18}$ The second terms (rather than the first ones) in the numerator and denominator would drive the results.
} 
Proposition 1. At the second-best optimum, when individuals differ in terms of productivity and demographic characteristics,

- If survival probabilities and probabilities to become dependent are identical across individuals, the standard Atkinson-Stiglitz (1980) result holds: optimality can be attained by only imposing a marginal tax on the income of the low-productivity individuals.

- If individuals also differ in their demographic characteristics, in addition to income taxation, it will be optimal, in general, to also tax early bequests of the low-productivity individuals.

- Late bequests should never be taxed or subsidised.

This proposition shows that in order to relax incentive constraints (due to the unobservability of individuals' productivity and demographic characteristics by the government), it is in general optimal to tax early bequests of the low-productivity individuals, when agents differ not only in productivity but also in their survival probability and probability to become dependent. Importantly, this result relies on Lefebvre et al. (2018), which shows that the magnitude of the relationship between wealth and survival is higher than the magnitude of the relationship between wealth and dependency. If there was no other difference than differences in productivity, and because preferences are separable, only the taxation of labour would be necessary, as in the standard model of Atkinson-Stiglitz (1980).

Let us then explain why taxing the early bequests of the low-productivity agents is, in general, optimal at the second-best optimum. Note first that the existence of precautionary savings whose magnitude depends on income and demographic characteristics, is a direct consequence of the absence of annuity and of LTC insurance markets. Second, and to start with, let assume the simplest case where the probability to be unhealthy at the old age is the same across individuals. Since, in that simplified scenario, type-2 individuals have higher survival probability and higher wages than type-1 individuals, they wish to make more precautionary savings (i.e. $s_{2}$ ), which results in higher early bequests $\left(b_{2}^{E}\right)$ if they die at the end of the first period. Hence, distorting downward the early bequests of type- 1 agents is a way to make their allocation less desirable to a type-2 individual and thus, prevent him from mimicking type-1 agents. Let us now assume that survival probabilities are the same but that individuals face different probabilities to be unhealthy at the old age. Following Lefebvre et al (2018), we have that $p_{1}>p_{2}$ which means that type- 1 individuals would like to make more precautionary savings than type- 2 individuals. Distorting upward the precautionary savings (by subsidizing them) of type-1 agents would make their allocation less desirable to type- 2 agents, with lower probability to become dependent and thus lower willingness to save.

Finally, in the general case, individuals differ both in their probability to become dependent and in their survival probability, such that $\pi_{2}>\pi_{1}$ and $\pi_{1} p_{1}>\pi_{2} p_{2}$. As stated above, the 
difference in survival is larger than the difference in the (unconditional) probability to become dependent so that the impact of the difference in survival dominates that of the difference in the probability to become dependent. This results in marginal taxation of the early bequests of low-type individuals.

Finally, we find that there should be no marginal taxation of late bequests (either in good health or under dependency) of type-1 agents. The main reason why the two types of late bequests are not taxed comes from the fact that in the second period of life, uncertainty has already realized and demographic characteristics play no role anymore. Agents are then forced to make consumption reallocation, once they have learnt their health status in the second-period. This implies that the choices of those late bequests are the same in the laissez-faire, the first-best and the second-best (i.e. 9 and 10 are identical to 14 and 15 .

\section{Conclusion}

This paper has studied the design of an optimal non linear inheritance taxation in a setting where individuals differ in wage as well as in their risks of both mortality and old-age dependance. We assume, as shown by Lefebvre et al. (2018) that higher-wage individuals have higher survival chances and lower probability to become dependent. In our model, agents exhibit a joy of giving bequest motive and as observed in reality, we assume that there is no perfect annuity or LTC insurance market. This leads to having three types of bequests depending on the realization of nature: early bequests, late bequests under autonomy and late bequests under dependency. The government cannot distinguish between bequests motives, that is whether bequests result from precautionary reasons or from pure joy of giving reasons. Instead, it only observes the timing of the donation, that is whether bequests are made early in life or late in life and in the latter case, whether the donor was healthy or not. In that setting, we show that in a second-best framework where the government cannot observe productivity and demographic characteristics, in addition to labour income taxation, the early bequests of the low-productivity agent should be distorted downward, i.e. they should be taxed at the margin, so as to make the problem incentive compatible. To the opposite, late bequests (either under autonomy or under dependency) should not be taxed at the margin.

Our paper contributes to the literature on the optimal taxation of inheritance, by adding to a standard Atkinson-Stiglitz (1980) model, the possibility that agents who care about the bequests they leave, become dependent at the old-age, a dimension that is largely absent in that literature. The advent of old-age dependency has become an increasing concern for policy makers in many developed countries. As such, our paper also contributes to a better understanding of these issues, and to how the taxation of bequests should be adapted to account for these new societal challenges. 


\section{References}

[1] Atkinson A. and J. Stiglitz, 1980, Lectures on public economics. McGraw-Hill, New York.

[2] Blumkin, T. and E. Sadka, 2003, Estate taxation with intended and accidental bequests. Journal of Public Economics, 88, 1-21.

[3] Boadway, R., Marchand, M. and Pestieau, P., 2000, Redistribution with unobservable bequests: a case for taxing capital income. Scandinavian Journal of Economics 102, 253-267.

[4] Brown, J. R. and A. Finkelstein, 2009, The private market for long-term care insurance in the United States: a review of the evidence. Journal of Risk and Insurance, 76(1), 5-29.

[5] Brunner J. and S. Pech, 2012, Optimal taxation of bequests in a model with initial wealth. Scandinavian Journal of Economics, 114 (4), 1368-1392.

[6] Canta C., P. Pestieau, and E. Thibault, 2016, Long-term care and capital accumulation: the impact of the State, the market and the family. Economic Theory, 61, 755-785.

[7] Cremer, H., Pestieau, P., and Rochet, J.-Ch., 2003, Capital income taxation when inherited wealth is not observable. Journal of Public Economics 87, 2475-2490.

[8] Cremer H. and P. Pestieau, 2006, Wealth transfer taxation: a survey of the theoretical literature. Chapter 16 in Handbook of the Economics of Giving, Altruism and Reciprocity, Vol. 1, 1107-1134 Elsevier North Holland, Amsterdam.

[9] Cremer, H., F. Gavahri and P. Pestieau, 2012, Accidental bequests: a curse for the rich and a boon for the poor. Scandinavian Journal of Economics, 114(4), 1437-1459.

[10] Cremer H. and P. Pestieau, 2014, Social long-term care insurance and redistribution. International Tax and Public Finance, 21, 955-974.

[11] De Donder P., and M-L. Leroux, 2014, Behavioral biases and long-term care insurance: a political economy approach. B.E Journal of Economic Analysis and Policy, 14(2), 551-575.

[12] De Donder P., and M-L. Leroux, 2017, The political choice of social long term care transfers when family gives time and money. Social Choice and Welfare, 49 (3-4), 755-786.

[13] Delavande A. and S. Rohwedder, 2011, Differential survival in Europe and the United States: estimates based on subjective probabilities of survival. Demography, 48(4), 1377-1400.

[14] Farhi, E. and I. Werning, 2013, Estate taxation with altruism heterogeneity. American Economic Review, Papers and Proceedings, 103 (3), 489-495. 
[15] Fleurbaey, M., M-L. Leroux, P. Pestieau, G. Ponthiere and S. Zuber, 2021, Premature deaths, involuntary bequests and fairness. Accepted Scandinavian Journal of Economics.

[16] Glomm G. and B. Ravikumar, 1992, Public versus private investment in human capital: endogenous growth and income inequality. Journal of Political Economy, 100(4), 818-834.

[17] Hurd, M., 1989, Mortality risk and bequests. Econometrica, 57(4), 779-813.

[18] Klimaviciute, J. and P. Pestieau, 2018, Long-term care social insurance: How to avoid big losses?. International Tax and Public Finance, 25(1), 99-139.

[19] Kopczuk, W. and J.P. Lupton, 2007, To Leave or not to leave: the distribution of bequest motives. The Review of Economic Studies, 74(1), 207-235.

[20] Lefebvre M., Perelman S., Schoenmaeckers J., 2018, Inégalités face à la mort et au risque de dépendance. Revue Française d'Economie, 33, 75-112.

[21] Leroux M-L. and P. Pestieau, 2021, Age related taxation of bequests in the presence of dependency risk. Available at https://doi.org/10.1111/jpet.12539.

[22] Mill, John Stuart (1848), Principles of Political Economy. Eds: John W. Parker, London.

[23] Mirrlees, J., 1971, An exploration in the theory of optimum income taxation. The Review of Economic Studies, 38(2), 175-208.

[24] OECD, 2018, The role and design of net wealth taxes in the OECD. OECD Tax Policy Studies, Paris.

[25] Pestieau, P. and M. Sato, 2008, Estate taxation with both accidental and planned bequests. Asia-Pacific Journal of Accounting \& Economics, 15, 223-240.

[26] Pestieau, P. and G. Ponthiere, 2011, The long term care insurance puzzle. In Financing Long-Term Care in Europe - Institutions. J. Costa-Font, palgrave macmillan edition.

[27] Pestieau, P. and G. Ponthiere, 2019, An age differentiated tax on bequests. In Age Policies - Normative Theory and Proposals, ed. by Greg Bognar and Axel Gosseries, forthcoming.

[28] Piketty, T. and E. Saez, 2013, A theory of optimal inheritance taxation. Econometrica, Vol. 81 (5), 1851-1886.

[29] Vickrey, William, 1945, An integrated successions tax. Republished in: R. Arnott, K. Arrow, A. Atkinson and J. Dreze (eds.) (1994). Public Economics. Selected Papers by William Vickrey. Cambridge University Press. 